\title{
What Moves You? Testing Personality Characteristics for Transportability in Entertainment \\ Meade T*
}

Regis College, USA

\begin{abstract}
Have you ever seen an emotionally moving film? Many films and narratives have the power to transport the viewer to a different world with an immersive story. The viewer becomes so involved in the plot that they feel as if they may be experiencing the highs and lows with the main characters. Why was that film moving? Green and Brock identified the concept of Transportation in narrative. Transportation leads the viewer to â suspend disbelief, âbe entertained, and even persuaded. Why were you moved, but others were not? Green and Brockâs research studied the effects of various plot devices and narrative voices to determine how a viewer is transported into the story.
\end{abstract}

Keywords: Transportation; Entertainment

\section{Introduction}

Have you ever seen an emotionally moving film? Many films and narratives have the power to transport the viewer to a different world with an immersive story. The viewer becomes so involved in the plot that they feel as if they may be experiencing the highs and lows with the main characters. Why was that film moving? Green and Brock identified the concept of Transportation in narrative [1]. Transportation leads the viewer to "suspend disbelief," be entertained, and even persuaded [2]. Why were YOU moved, but others were not? Green and Brock's research studied the effects of various plot devices and narrative voices to determine how a viewer is transported into the story. Though Green and Brock took some personality variables into account, the goal of this research is to identify personality variables that may lead to transportation in any narrative (or as later termed, "transportability") by building a model of transportation. The goal of this study is to answer the question, who is likely to be transported?

\section{Transportability}

Transportation originated in works by Nell and Gerrig [3,4]. Green [5], Green and Brock [6], Green, Brock, and Kaufman [7], Green, Garst, and Brock [8], has studied the concept through various avenues, including scale creation, and model creation [1]. Green also accounted for narrative variables such as prior knowledge and perceived realism. The study of transportation is often viewed through a persuasive lens $[1,5]$. Green and Brock noted that transportation is a process of absorption, which leads the viewer to change their real world beliefs [1]. This lends well to persuasive study, as a narrative low in transportation is unlikely to be persuasive. Further, transportation differs from other divergent persuasive theories such as the Elaboration Likelihood Model and the Heuristic Systematic Model $[9,10]$.

Transportation has been regarded as the narrative's ability to "transport" the viewer into the world of the narrative, leaving the viewer with a feeling of immersion into the narrative. In simplest terms, transportation is the act of being "swept away" into the world of the narrative, be it fictional or non-fictional. Transportation, however, does differ from the term involvement in one very specific way- the viewer must be in some way changed from the narrative; this lends transportation greatly to studies of persuasion [1].

Though transportation is highly associated with persuasion, it has also been found to heighten the entertainment experience [2,11-14]. A highly engrossing narrative causes an individual to use more resources in order to process the information presented in the narrative, leaving fewer resources available for narrative scrutiny. This leads to a more engrossed viewer; taking on all the trials and tribulations the plotline has to offer along with the main characters. This engrossing process leads to less counterarguments going on in one's thoughts, and, therefore, higher enjoyment of the narrative [6].

Overall, a narrative tends to be highly transportable or not, in that it is written or produced in such a way that it lends highly to one being transported into the story [1]. However, just as with any other measurable characteristic, humans will likely vary greatly in the extent to which they are actually transported into a story. This could be due to writing styles, identification with a character, or, as this study will test, the personality characteristics of an individual [1]. Therefore, a measure of "transportability," or an individual's willingness and ability to be transported into a narrative, will be tested against various personality characteristics. These measures could help to fully understand how an individual is transported into a narrative.

\section{The Big Five}

The Big Five personality characteristics are a set of personality traits that affect behavior and thought more than other traits. The Big Five personality characteristics break down personality into five segments: agreeableness, neuroticism, extraversion, conscientiousness, and intellect/imagination (or openness) [15].

\section{Agreeableness}

Agreeableness is a warm personality trait that involves showing a deep caring for others. Overall, agreeableness is a sign of friendliness, altruism, and social support, while being negatively correlated to aggression and anger [16]. Agreeableness has been studied in reference to self-efficacy, dependency, and empathy [17-19]. Graziano et al.

${ }^{*}$ Corresponding author: Meade T, Regis College, USA, Tel: 17817687000 E-mail: tmeade4@gmail.com

Received July 21, 2015; Accepted September 09, 2015; Published Septembe 19, 2015

Citation: Meade T (2015) What Moves You? Testing Personality Characteristics for Transportability in Entertainment. J Mass Communicat Journalism 5: 274. doi:10.4172/2165-7912.1000274

Copyright: (c) 2015 Meade T. This is an open-access article distributed under the terms of the Creative Commons Attribution License, which permits unrestricted use, distribution, and reproduction in any medium, provided the original author and source are credited. 
found a relationship between agreeableness and empathy, therefore leading to the first hypothesis [19]:

H1: Agreeableness will be correlated positively with empathy.

This led to the second hypothesis (which will be justified when discussing empathy):

H2: Agreeableness will be correlated positively to transportability.

\section{Neuroticism}

Neuroticism is often studied in relation to psychological disorder and is associated with feelings of anxiety and depression. Neurotics easily identify with negative social situations, and have been found to react highly to negative situations in film [20]. Narratives can have a positive or negative message, or both. It would seem that the neurotic individual would likely identify with the negative message, however, it is less likely that they would identify with the positive message. This led to the first research question:

\section{RQ1: Is neuroticism related to transportability?}

\section{Extraversion}

Extraversion is a characteristic associated with seeking stimulation outside of oneself. An extravert will often look to others for social stimulation, thus associating the term and those individuals displaying the characteristic with friendliness, likeableness, and social adroitness [21]. Because these individuals are likely to seek stimulation outside of themselves, they will likely be more willing to transport to a narrative. Therefore, the third hypothesis is forwarded:

H3: Extraversion will be correlated positively with transportability.

It may also be possible that an extravert, because they will seek stimulation outside of oneself, will be more likely to feel empathy towards others.

H4: Extraversion will be correlated positively with empathy.

\section{Conscientiousness}

Conscientiousness is characterized by strong motivation and cooperation. Conscientious individuals tend to be hypercompetitive, and the measure correlates negatively with avoidance [22]. Overall, a conscientious individual is a motivated hard-worker. Because conscientiousness is associated with being motivated and a hard worker, it is likely that it will be related to need for cognition. Therefore, the next hypothesis is offered:

H5: Conscientiousness will be correlated positively to need for cognition

Green and Brock found no interaction between need for cognition and transportation [1]. Therefore, it is likely that:

H6: There will be no significant relationship between conscientiousness and transportability.

\section{Intellect/Imagination}

Donnellan liken intellect/imagination to the trait "openness." Openness is the more common term for this trait in research [23]. However, transportability is associated with imagination, as that may have a higher correlation to transportability. Imagination is a term likened to creativity or thoughtfulness; even ability to visualize or envision [23]. Because imagination is a term most closely associated with the ability to create a vivid image in your head, it is likely that this will be related to transportability, empathy, and fantasy proneness. This led to the next hypotheses:

H7: Intellect/Imagination will be correlated positively to transportability.

H8: Intellect/Imagination will be correlated positively to empathy

H9: Intellect/Imagination will be correlated positively to fantasy proneness.

\section{Need for cognition}

Need for cognition is a measure of how much one enjoys thinking $[9,24]$. An individual high in need for cognition will often be highly motivated to challenge themselves, and highly motivated to avoid failure, much like conscientiousness [22,25]. Green and Brock studied need for cognition and transportation and found no relationship existed between the two [1].

H10: There will be no significant relationship between need for cognition and transportability.

High need for cognition in narrative could possibly fall under two categories: a high enjoyment category or a low enjoyment category. In the high enjoyment category, it is likely that the consumer will be thinking very hard about the plot, and the plot satisfies this consumer's needs. In the low enjoyment category, a plot requires much less thinking, and will not satisfy the consumer's needs. It is possible these categories may moderate the relationship between need for cognition and transportability. An individual who is high in need for cognition may not find many narratives intellectually stimulating, and therefore, may not allow themselves to "transport" into the plot. Or, they may find many narratives intellectually stimulating. If there is no significant positive relationship between need for cognition and transportability on its own, it is possible that enjoyment will moderate the relationship between need for cognition and transportability. Therefore, the next research question is posed:

RQ2: Is there any relationship between need for cognition and transportability when accounting for enjoyment of the narrative?

\section{Fantasy proneness}

The fantasy prone individual is one whom is highly likely to be deeply absorbed in fantasy, with the ability to fantasize most of the day, and even "experience" their fantasies through hallucinations [26]. Those high in fantasy proneness are often easily hypnotized, believe they have experienced paranormal encounters or have the ability to experience them, and can easily dissociate themselves from a situation, though dissociation is often tied to a psychological disorder or hypnosis [27-32].

The ability to fantasize requires a great imagination, with an ability to place yourself somewhere you are not. This should be highly related to transportability. Therefore, the next hypothesis is offered:

H11: Fantasy proneness will correlate positively to transportability.

\section{Empathy}

Empathy is a measure of how well one can understand and respond to another's emotions [33]. Empathy will occur when one individual recognizes an emotion in another, and because of this recognition, feels the same emotion. Empathy differs from sympathy in that empathy includes a mutual emotion, whereas sympathy is only the recognition of a negative state [33]. 
Because empathy is measured as the ability to recognize and experience an emotion in congruence with another individual, and transportability is the person's propensity to experience a plotline in congruence with a main character, hypothesis twelve is forwarded:

H12: Empathy will correlate positively with transportability.

\section{Defining “Transportability" by developing a model}

The goal of this study is to define the personality characteristics that support transportation to a narrative. Using each of the personality characteristics mentioned previously, as well as measures of usage and enjoyment of narratives, a model of best fit will be developed to clearly outline the relationships amongst the variables accounted for in this study. The model will be developed based on the correlational analyses of each hypothesis and research question.

\section{Method}

\section{Participants}

A total of 207 participants (Male $=62$, Female $=144$ ) were recruited from multiple low level mass communication classes. Participation was awarded with class credit. Participant's age ranged from 17-26. Reported races were Caucasian (87.9\%), African American (8.2\%), Native American (1.4\%), Hispanic (1.0\%), Asian/Pacific Islander (0.5\%), and Multi-Racial (0.5\%).

\section{Procedure}

The questionnaire was posted online, where the participants could complete the survey for credit. Each scale was in a Likerttype format. The questionnaire consisted of five separate scales. An initial examination of a CFA revealed four items that would improve the model for better fit if dropped. All further analyses reflect these omissions (including reliability, mean, and standard deviation).

The scales included were the Transportation Scale; Mean $=58$, $\mathrm{SD}=8, \alpha=.77$ [1], which was manipulated to reflect all narratives, a Need for Cognition Scale; Mean=97, $S D=16, \alpha=.87$ [34], a Fantasy Proneness Scale; Mean $=35, \mathrm{SD}=7, \alpha=.79$ [35], an Empathy Scale; Mean 89, $S D=13, \alpha=.88$ [33], and a Big Five Scale; ExtraversionMean=21, $\mathrm{SD}=5, \alpha=.83$ [23]; Agreeableness- Mean=22, $\mathrm{SD}=4, \alpha=.71$; Conscientiousness- Mean $=19, \mathrm{SD}=5, \alpha=.71$, Neuroticism- Mean $=15$, $\mathrm{SD}=5, \alpha=.67$; Imagination- Mean $=21, \mathrm{SD}=4, \alpha=.72$ ).

The Transportation Scale was manipulated so that it would reflect "transportability" rather than transportation to a specific narrative [1]. Previously, this scale would be used to test the transportation characteristics of a narrative (i.e. a respondent would read a narrative and then complete the Transportation Scale in reference to that narrative). In this study, the items were slightly manipulated to reflect a respondent's propensity for transportation. For example, an item in the original Transportation Scale read, I could picture myself in the scene of the events described in the narrative. This item was changed to read, I can picture myself in the scene of the events of most narratives. The word narrative was defined for the respondents as "the plot of movies, television shows, books, etc." These changes did not negatively affect the reliability of the measure, and were subject to a short pretest $(n=20)$ to ensure reliability and validity.

\section{Results}

\section{The big five}

Hypotheses one through nine were all supported. Further examination of the values can be found in Table 1: Correlation Matrix. Research question one asked if a significant relationship existed between neuroticism and transportability. Results of a Pearson correlation indicate that there is no significant relationship $(\mathrm{r}=-.01, \mathrm{p}=.86)$. There is no positive or negative correlation between neuroticism and transportability.

Need for Cognition: Hypothesis ten forwarded no significant relationship existed between need for cognition and transportability. Results of a Pearson correlation indicate that this relationship is significant $(\mathrm{r}=.74, \mathrm{p}<.001)$. Hypothesis ten is not supported. Unlike previous research, need for cognition is found to be related to transportation [1]. Perhaps the difference may be seen in the measurement. Green and Brock measured specifically written narrative, whereas this research focused on all forms of entertainment. This may also be explained by the nature of the research. Green and Brock were studying transportation in persuasion, not entertainment [1]

Research question two asked if any relationship existed between need for cognition and transportability when accounting for enjoyment of the narrative. The results of hypothesis ten were not supported; therefore, a significant relationship exists even when not accounting for enjoyment of the narrative. This will be further explored post hoc.

Fantasy proneness: Hypothesis eleven forwarded a significant positive relationship between fantasy proneness and transportability. Results of a Pearson correlation indicate that this relationship is significant $(\mathrm{r}=.53, \mathrm{p}<.001)$. Hypothesis ten is supported.

Empathy: Hypothesis twelve forwarded a significant positive relationship between empathy and transportability. Results of a Pearson correlation indicate that this relationship is significant $(\mathrm{r}=.36$, $\mathrm{p}<.001)$. Hypothesis eleven is supported.

All hypotheses but hypothesis ten were supported. Further, this research contrasted previous research in that need for cognition was related to transportation. Though most hypotheses were supported, further investigation into the entertainment factors is needed. Therefore, post hoc tests were done to determine which characteristics may correlate with usage and enjoyment of genres, overall usage and enjoyment, and finally, which characteristics may account for variance in transportation. All correlations are displayed in Table 1, while all significant correlations to transportability are displayed in Table 2.

Post hoc: The purpose of this study is to determine which specific personality characteristic variables are important in determining transportability. The characteristics studied here are need for cognition, fantasy proneness, empathy, and the Big Five (extraversion, agreeableness, conscientiousness, neuroticism, and intellect/ imagination). However, not all of these variables positively correlated to transportability. Therefore, a regression analysis was only run on those characteristics that were seen to positively correlate with transportability.

This study has been concerned with the ability of personality characteristics, specifically, need for cognition, fantasy proneness, empathy, extraversion, agreeableness, and intellect/imagination, to predict transportability into a narrative. Using multiple regressions, transportability scores were regressed on the linear combination of the six predictor variables. The equation containing these three variables accounted for $51 \%$ of the variance in transportability ( $F(147)=25.36$, $\mathrm{p}<.001)$. A closer examination of the beta weights revealed that need for cognition $(\beta=.24)$, fantasy proneness $(\beta=.32)$, agreeableness 


\begin{tabular}{|c|c|c|c|c|c|c|c|c|c|c|c|c|c|c|c|c|c|}
\hline \\
\hline \multicolumn{3}{|c|}{ (1) (2) } & (3) & (4 & 4) & 5) & (6) & (7) & (8) & (9) $\quad(10$ & 10) $\quad(1$ & 11) (12) ( & (13) 1 & (14) & (15) & (16) & (17) \\
\hline 1. & Transportation & - & & & & & & & & & & & & & & & \\
\hline 2. & Need for Cognition & $.74^{*}$ & - & & & & & & & & & & & & & & \\
\hline 3. & Fantasy Proneness & $.53^{*}$ & $.25^{*}$ & - & & & & & & & & & & & & & \\
\hline 4. & Empathy & $.36^{\star}$ & $.21^{*}$ & $.40^{*}$ & - & & & & & & & & & & & & \\
\hline 5. & Extraversion & $.17^{*}$ & .12 & $.19^{*}$ & $.41^{*}$ & - & & & & & & & & & & & \\
\hline 6. & Agreeableness & $.46^{*}$ & $.29^{*}$ & $.42^{*}$ & $\star .79^{*}$ & $.51^{*}$ & - & & & & & & & & & & \\
\hline 7. & Conscientiousness & -.01 & $.18^{*}$ & -.05 & $.17^{*}$ & $.15^{*}$ & $.15^{*}$ & - & & & & & & & & & \\
\hline 8. & Neuroticism & -.01 & -.02 & $.14^{*}$ & .01 & -.12 & .02 & .00 & - & & & & & & & & \\
\hline 9. & Intellect/Imagination & $.50^{*}$ & $.48^{*}$ & $.41^{*}$ & $.37^{*}$ & $.23^{*}$ & $.47^{*}$ & .04 & .00 & - & & & & & & & \\
\hline 10. & Overall Drama & $.21^{*}$ & $.19^{*}$ & $.32^{*}$ & $.21^{*}$ & -.04 & .15 & .12 & .10 & .11 & - & & & & & & \\
\hline 11. & Overall Comedy & .07 & .13 & $.21^{*}$ & $\star .09^{*}$ & $.14^{*}$ & .14 & -.03 & -.08 & $.15^{*}$ & .02 & - & & & & & \\
\hline 12. & Overall Mystery & $.20^{*}$ & $.23^{*}$ & $.15^{*}$ & -.01 & $.16^{*}$ & .11 & .13 & -.09 & $.17^{*}$ & .15 & .06 & & & & & \\
\hline 13. & Overall Sci-Fi & $.32^{*}$ & $.24^{*}$ & $.29^{*}$ & -.05 & -.14 & .05 & -.03 & .10 & $.28^{*}$ & $.23^{*}$ & $.09 \quad .30^{*}$ & - & & & & \\
\hline 14. & Overall Romance & .14 & -.07 & $.25^{\star}$ & $.22^{*}$ & * $.18^{*}$ & $.25^{*}$ & .03 & $.15^{*}$ & -.03 & $.23^{*}$ & $.19^{*}-.04$ & -.01 & - & & & \\
\hline 15. & Overall Horror & -.04 & -.02 & .11 & -.03 & .02 & -.08 & -.07 & .01 & .06 & -.06 & $.02 \quad .38^{*}$ & .17 & .02 & - & & \\
\hline 16. & Overall Usage & $.34^{*}$ & .16 & $.42^{*}$ & $.21^{*}$ & .01 & .15 & .04 & .11 & $.22^{*}$ & $.54^{*}$ & $.40^{*} 51^{*}$ & $.57^{\star}$ & $.47^{*}$ & $.49^{*}$ & - & \\
\hline 17. & Overall Enjoyment & $.24^{*}$ & $.27^{\star}$ & $.42^{*}$ & .25 & .06 & $.27^{*}$ & .09 & .09 & $.31^{*}$ & $.56^{*}$ & $.30^{*} .56^{*}$ & $.55^{*} .4$ & $.48^{*}$ & $.54^{*}$ & $.82^{*}$ & - \\
\hline
\end{tabular}

Note: $\mathrm{p}<.05$ asterisked, $\mathrm{p}<.01$ in bold and asterisked

Table 1: Correlation Matrix of All Variables.

Significant Correlations of Transportation (asterisked $=p<.01$ )

\begin{tabular}{|c|c|c|c|c|c|c|c|c|}
\hline & \multicolumn{2}{|c|}{ Need for Cog. Fantasy Pron€ } & \multicolumn{2}{|c|}{ Empathy Agreeableness } & \multicolumn{4}{|c|}{ Intellect/Imagination Drama Mystery Sci-Fi Usage Enjoyment } \\
\hline Transportation & $.46^{*}$ & $.53^{*}$ & $.36^{*}$ & $.46^{*}$ & $.50^{*}$ & $.21^{*}$ & $.20 *$ & $.34^{*}$ \\
\hline
\end{tabular}

Table 2: Significant Correlations of Transportation.

Significant Characteristic Variables Accounting for Variance in Transportation

Need for Cognition

Fantasy Proneness

$.24^{* *}$

Agreeableness

Intellect/Imagination

Note: ${ }^{*} p<.01,{ }^{* *} p<.001$

Table 3: Significant Characteristic Variables Accounting for Variance in Transportation.

( $\beta=.32)$, and intellect/imagination $(\beta=.21)$ were significantly related to transportability (Table 3 ).

An individual's transportability may also depend on the genre of narrative. A more fantastic story may require more transportation. Therefore, those genres that were significantly positively correlated to transportability were also tested.

Using multiple regressions, transportability scores were regressed on the linear combination of the five predictor variables. The equation containing these three variables accounted for $18 \%$ of the variance in transportability $(\mathrm{F}(94)=4.07, \mathrm{p}=.002)$. A closer examination of the beta weights revealed that science fiction $(\beta=.24)$ and mystery $(\beta=.31)$ were significantly related to transportability.

These findings have supported the idea that both personality characteristics and the specific genre usage and enjoyment both play a role in a person's transportability.

Model development: $\mathrm{Hu}$ and Bentler and Brown and Cudeck suggested that models be assessed using a nonnormed fit index (NFI) and comparative fit index (CFI) of greater than .90, a root mean square error of approximation (RMSEA) of less than .05 (or between .05 and
08 to indicate a reasonable fit), and a non-significant chi-square value (though a sample size larger than 200 will likely affect this outcome [36-38]. However, recent research has suggested that NFI and CFI measures be above .95 for best fit [38].

The goal of this study is to develop a model of transportability. The first two steps identified significant correlations with transportability as well as variables accounting for variance in transportability. These two steps have identified six variables: need for cognition, fantasy proneness, agreeableness, intellect/imagination, usage and enjoyment of science fiction, and usage and enjoyment of mystery.

Available combinations of these variables produced no models nearing an acceptable fit. Therefore, empathy was added to the model. This was the only variable that displayed a significant correlation to transportability, but did not significantly predict transportability. However, when the two Big Five traits and the two usage traits were replaced by empathy, the model began to approach acceptability. All data were analyzed using AMOS.

According to the criteria of $\mathrm{Hu}$ and Bentler and Browne and Cudeck, the model of need for cognition, fantasy proneness, and empathy predicting transportability approached acceptability

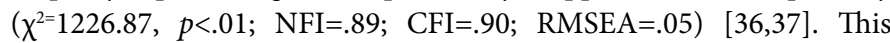
model only approaches acceptability because the NFI does not meet the standard and the chi-square value is significant. However, the other measures are acceptable. The chi-square value is likely significant due to the sample size [38]. This model can be found in Figure 1. Recent research would not accept this model. Hooper, Coughlan, and Mullen explicitly stated that NFI and CFI values should be above .95; these are criteria that these findings do not meet [38]. However, due to the exploratory nature of this research, these findings may be used as a means to begin study on transportability. 


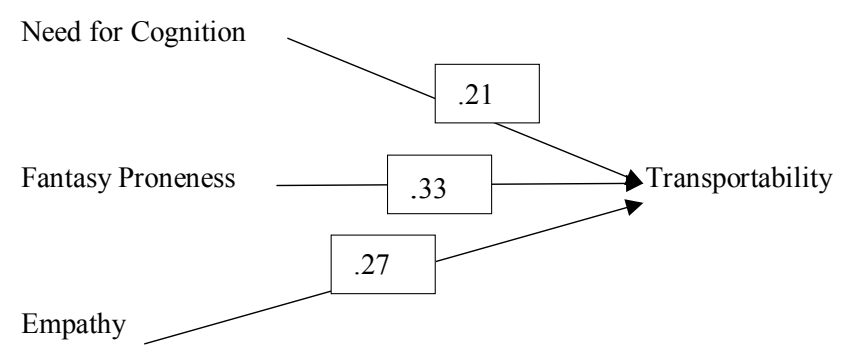

Figure 1: Model of Transportability.

\section{Discussion}

It was hypothesized that three of the Big Five, agreeableness, extraversion, and imagination would correlate positively to transportability. All three were found to have a significant positive relationship with transportability. However, extraversion was found to have the smallest correlation and did not have a significant beta weight in regression. Because extraversion is the propensity of an individual to look for stimulation outside of themselves, this is a surprising finding [21]. However, Cuperman and Ickes describe an extrovert as someone that is socially adept [21]. Therefore, due to the lack of interpersonal interplay between the extrovert and the characters, it is likely this relationship occurred because there is no way to reciprocate the interaction, therefore keeping the extrovert from achieving their outward stimulation.

Green and Brock found no relationship between need for cognition and transportation [1]. Need for cognition was found to correlate positively to transportability, and even accounted for variance in transportability. Why is this different from Green and Brock? [1]. As mentioned earlier, Green and Brock were focused mainly on persuasion, or the ability of a narrative piece to persuade you through transportation [1]. In this study, it is the entertainment feature of transportation that is being tested, rather than its ability to persuade. For example, Green and Brock were testing how one narrative at a time was able to persuade, not taking into account the entertainment aspect of transportation [1]. Those individuals willing to be transported who are also high in need for cognition may find certain narratives intellectually stimulating, and possibly seek those narratives out. For example, need for cognition also correlated positively with use and enjoyment of the genre mystery, which often requires or stimulates thought in the consumer. Therefore, it may be possible that an individual high in need for cognition is willing to transport in the right situation. Perhaps the narratives used by Green and Brock were not the type of entertaining material that may bring this out [1]. Also, Green and Brock were looking at specifically written narrative; this study took into account all available outlets of narrative entertainment [1].

\section{Theoretical Implications}

Green and Brock discussed their transportation-imagery model that accounted for various narrative elements, as well as cognitive outcomes of a persuasive narrative [6]. However, their focus has been mainly on persuasion $[1,6]$. This model attempts to account for personality characteristics that may lead one to be often transported.

Dal Cin, Zanna, and Fong tested transportability in narrative [39]. These researchers followed a similar methodology by slightly manipulating the Transportation Scale to reflect all narrative (written and spoken). Their research found that transportability led to transportation. However, they did not test the characteristics that led to transportability. Further, biological sex has been shown on numerous occasions to affect transportation to a story. Green and Brock originally reported sex differences in transportation, and various research has found that women are more likely to empathize with narratives than men $[1,40-44]$. These sex differences may help to explain why empathy did not account for variance, but did become an important predictor within the model.

Green has found that many characteristics may lead to transportation, including mood, similarity to characters, and a schema of similar narratives $[5,45,46]$. This research furthers these findings by accounting for multiple personality characteristics that do and do not lead to transportability. Surprisingly, none of the Big Five personality characteristics led to transportability in any way (directly, mediating, or moderating). Neither did any affinity for any specific genre. This is interesting because it suggests an even playing field for any narrative writing when speaking of genre.

This model found that need for cognition, empathy, and fantasy proneness all led to transportability. These variables each make sense when considering transportability as a personality characteristic. Though need for cognition had shown no previous relation to transportation, most of these studies had been completed testing one or two specific narratives. Further, much research has found that empathy should play a role in transportation [1]. Finally, fantasy proneness is conceptually similar to transportability.

This model helps to identify transportation's role in entertainment, and begins to differentiate it from its role in persuasion. However, it does not meet recent standards for structural equation modeling, and the CFI (a measure of the correlations between variables) does not meet any standards, but it does approach some [36-38]. Therefore, these findings must be taken in context and certainly need further examination.

\section{Future Research}

This study was limited by studying a college population that may be more attracted to certain types of entertainment, already high in need for cognition, or more willing to transport themselves overall. No measure of education was taken. This may be an avenue of future research. Future research should use these findings to determine if there is a way to accentuate transportation, and also look for more personality variables to account for variance in transportability. Specifically, future research should look into the tactics to employ in order to accentuate audience thought, imagination, and liking and caring for the characters involved.

\section{References}

1. Green MC, Brock TC (2000) The role of transportation in the persuasiveness of public narrative. Journal of Personality and Social Psychology 79: 701-721.

2. Bilandzic $\mathrm{H}$, Busselle RW (2008) Transportation and transportability in the cultivation of genre-consistent attitudes and estimates. Journal of Communication 58: 508-529.

3. Nell V (1990) Lost in a book: The psychology of reading for leisure. Yale University Press, New Haven, CT.

4. Gerrig R (1993) Experiencing narrative worlds: On the psychological activities of reading. Yale University Press, New Haven, CT.

5. Green MC (2004) Transportation into narrative worlds: The role of prior knowledge and perceived realism. Discourse Processes 38: 247-266.

6. Green MC, Brock TC (2002) Transportation-imagery model of narrative 
Citation: Meade T (2015) What Moves You? Testing Personality Characteristics for Transportability in Entertainment. J Mass Communicat Journalism 5: 274. doi:10.4172/2165-7912.1000274

Page 6 of 6

persuasion. In Green MC, Strange JJ, Brock TC (Eds.) Narrative impact: Social and cognitive foundations. Erlbaum, Mahwah, NJ.

7. Green MC, Brock TC, Kaufman GF (2004) Understanding media enjoyment: The role of transportation into narrative worlds. Communication Theory 14 311-327.

8. Green MC, Garst J, Brock T C (2004) The power of fiction: Determinants and boundaries. In Shrum LJ (Ed.), The psychology of entertainment media: Blurring the lines between entertainment and persuasion. Mahwah, $\mathrm{NJ}$ : Erlbaum.

9. Cacioppo JT, Petty RE (1982) The need for cognition. Journal of Personality and Social Psychology 42: 116-131.

10. Chaiken S (1980) Heuristic versus systematic information processing and the use of source versus message cues in persuasion. Journal of Personality and Social Psychology 39: 752-766.

11. Escalas JE (2007) Self-referencing and persuasion: Narrative transportation versus analytical elaboration. Journal of Consumer Research 33: 421-429.

12. Moyer-Gusé E, Nabi RL (2010) Explaining the effects of narrative in an entertainment television program: Overcoming resistance to persuasion. Human Communication Research 36: 26-52.

13. Wang J, Calder BJ (2006) Media transportation and advertising. Journal of Consumer Research 33: 151-162.

14. Batat W, Wohlfeil M (2009) Getting lost "Into the Wild": Understanding consumers' movie enjoyment through a narrative transportation approach. Advances in Consumer Research - North American Conference Proceedings 36: $372-377$

15. McCrae RR, Costa PT (2003) Personality in adulthood: A five-factor theory perspective. The Guilford Press, New York.

16. Nettle D, Liddle B (2008) Agreeableness is related to social-cognitive, but no social-perceptual, theory of mind. European Journal of Personality 22: 323-335.

17. Caprara GV, Alessandri G, DiGiunta L, Panerai L, Eisenberg N (2010) The contribution of agreeableness and self-efficacy beliefs to prosociality. European Journal of Personality 24: 36-55.

18. Lowe JR, Edmundson M, Widiger TA (2009) Assessment of dependency, agreeableness, and their relationship. Psychological Assessment 21: 543-553.

19. Graziano WG, Habashi MM, Sheese BE, Tobin RM (2007) Agreeableness, empathy, and helping: A person $X$ situation perspective. Journal of Personality and Social Psychology 93: 583-599.

20. Wasylkiw L, Fabrigar LR, Rainboth S, Reid A, Steen C (2010) Neuroticism and the architecture of the self: Exploring neuroticism as a moderator of the impact of ideal self-discrepancies on emotion. Journal of Personality 78: 471-492.

21. Cuperman R, Ickes W (2009) Big Five predictors of behavior and perceptions in initial dyadic interactions: Personality similarity helps extraverts and introverts, but hurts "disagreeables". Journal of Personality and Social Psychology 97 667-684.

22. Komarraju M, Karau SJ, Schmeck RR (2009) Role of the Big Five personality traits in predicting college students' academic motivation and achievement. Learning and Individual Differences 19: 47-52.

23. Donnellan MB, Oswald FL, Baird BM, Lucas RE (2006) The Mini-IPIP scales:Tiny-yet-effective measures of the Big Five factors of personality. Psychological Assessment 18: 192-203.

24. Haugtvedt CP, Petty RE (1989) Need for cognition and attitude persistence. Advances in Consumer Research 16: 33-36.

25. Steinhart Y, Wyer RS (2009) Motivational correlates of need for cognition European Journal of Social Psychology 39: 608-621.

26. Rhue JW, Lynn SJ (1987) Fantasy proneness: Developmental antecedents. Journal of Personality 55: 121-137.

27. Green JP, Lynn SJ (2008) Fantasy proneness and hypnotizability: Another look. Contemporary Hypnosis 25: 156-164.

28. Gow K, Lang T, Chant D (2004) Fantasy proneness, paranormal beliefs, and personality features in out-of-body experiences. Contemporary Hypnosis 21: 107-125

29. Parra A (2006) "Seeing and feeling ghosts": Absorption, fantasy proneness, and healthy schizotypy, as predictors of crisis apparition experiences. Journal of Parapsychology 70: 357-372.
30. Giesbrecht T, Lilienfeld SO, Lynn SJ, Merckelbach H (2010) Cognitive processes, trauma, and dissociation- misconceptions and misrepresentations: Reply to Bremner (2010). Psychological Bulletin 136: 7-11.

31. Pekala RJ, Angelini F, Kumar VK (2001) The importance of fantasy-proneness in dissociation: A replication. Contemporary Hypnosis 18: 204-214.

32. Silva CE, Kirsch I (1992) Interpretive sets, expectancy, fantasy proneness and dissociation as predictors of hypnotic response. Journal of Personality and Social Psychology 63: 847-856.

33. Spreng RN, McKinnon MC, Mar RA, Levine B (2009) The Toronto empathy questionnaire: Scale development and initial validation of a factor-analytic solution to multiple empathy measures. Journal of Personality Assessment 91 $62-71$

34. Lord KR, Putrevu S (2006) Exploring the dimensionality of the Need for Cognition Scale. Psychology \& Marketing 23: 11-34.

35. Davis MH (1980) A multidimensional approach to individual differences in empathy. JSAS Catalog of Selected Documents in Psychology 10: 85

36. Hu L, Bentler PM (1999) Cutoff criteria for fit indexes in covariance structure analysis: Conventional criteria versus new alternatives. Structural Equation Modeling 6: 1-55.

37. Browne MW, Cudeck R (1993) Alternative ways of assessing model fit. In Bollen KA, Long JS (Eds.) Testing structural equation models. Sage, Newbury Park, CA.

38. Hooper D, Coughlan J, Mullen M (2008) Structural equation modelling Guidelines for determining model fit. Electronic Journal of Business Research Methods 6: 53-60.

39. Dal Cin S, Zanna MP, Fong GT (2004) Narrative persuasion and overcoming resistance. In Knowles ES, Linn JA (Eds.) Resistance and persuasion. Erlbaum, Mahwah, NJ

40. Ang I, Couling D (1985) Watching Dallas: Soap opera and the melodramatic imagination. Methuen, London.

41. Argo JJ, Zhu R, Dahl DW (2008) Fact or fiction: An investigation of empathy differences in response to emotional melodramatic entertainment. Journal of Consumer Research 34: 614-23.

42. Davis MH (1983) Measuring individual differences in empathy: Evidence for a multidimensional approach. Journal of Personality and Social Psychology 44 113-26.

43. Stern BB (1992) Feminist literary theory and advertising research: A new "reading" of the text and the consumer. Journal of Current Issues \& Research in Advertising 14: 9-21.

44. Stern BB (1993) Feminist literary criticism and the deconstruction of ads: A postmodern view of advertising and consumer responses. Journal of Consumer Research 19: 556-66.

45. Green MC, Chatham C, Sestir MA (2012) Emotion and transportation into fact and fiction. Scientific Study of Literature 2: 37-59.

46. Mazzocco P, Green MC, Brock TC (2007) The effects of a prior storybank on the processing of a related persuasive communication. Media Psychology 10 64-90. 